\title{
Study of the Effect of Dynamic Assessment and Graphic Organizers on EFL Learners' Reading Comprehension
}

\author{
Malahat Shabani Minaabad \\ Department of Linguistics and English Language Teaching, Payame Noor University, PO BOX 19395-3697 Tehran, \\ Iran
}

\begin{abstract}
Reading skill is one of the four skills which is very important to gain knowledge and very essential for academic life. The main focus of instructing this skill is on comprehension (Schunder, 1992). Among different factors important in comprehending expository text; the text structure, known as organizational pattern and related pictures plays a key role (Armbruster, Anderson, \& Ostertag, 1987). The aim of this study was to examine the effects of two reading comprehension strategies, i.e., Dynamic Assessment (DA) and Graphic Organizers (GO) on EFL learners' reading comprehension ability. Forty five elementary students were randomly assigned to two experimental groups (A, B) and one control group (C). Students in group A received Dynamic Assessment (DA) and those in group B received Graphic Organizing instruction (GO). Students in control group $C$ were instructed traditionally. After 10 sessions, they were post-tested. The statistical tool of the Kruskal-Wallis Test was run to determine if there was significant difference. The results of the study showed that both experimental groups acted better than the control group on the reading comprehension. It should also be noted that because of relative superiority of DA group over TI, it is more logical to prioritize DA as a better choice. Nonetheless, GO group was placed somewhere in the middle among these three groups.
\end{abstract}

Index Terms — dynamic assessment, graphic organizers, reading comprehension, EFL learners

\section{INTRODUCTION}

Reading is one of the four skills in language learning that has great role in learner's future academic life and career success, in which comprehension must take place. As children get older, they are faced with reading and responding to content area material presented in classes such as science and social studies, which are expository in nature and qualitatively different from narrative texts. Students often experience difficulty with the transition from "learning to read" to "reading to learn" and this point is one of the main issues that not only EFL students but also most of the first language readers face. Unfortunately, this problem originated in learners because they do not know how to read meaningfully; in fact they are not equipped with different kinds of strategies in order to deal with this problem, and they are accustomed to the traditional method in which the instructor introduces the text and asked them to read and answer the questions with his/her help, which was mainly with no comprehension. So, being able to comprehend and respond to expository texts is critical for most students. L2 learning specialists claim there are different reasons for this shortage: one of them is the lack of expository materials in the early grade classroom; in addition to that, expository texts may be more difficult to comprehend than narrative texts. Expository passages often present readers with unfamiliar concepts, new vocabulary, and complex relationships between ideas (Griffin \& Tulbert, 1995), with a greater density of information per sentence. Finally, the structural designs underlying expository texts differ from the simple story structures of narrative texts (Cain, Oakhill, \& Bryant, 2004; Meyer \& Ray, 2011). Thus, students who are accustomed to narrative texts are suddenly confronted with both unfamiliar content and unfamiliar organizational patterns when they enter the later grades.

The main objective of this study is to examine the effect of using two reading comprehension strategies i.e., dynamic assessment and graphic organizers on the students' reading comprehension. It was mostly justified by some theoretical facts, which are behind these two strategies and lend support them, such as schema theory which emphasize that learning should take place in an organizational patterns and will happen when the newly learned materials are integrated to one's existing cognitive framework of knowledge (Winn and Snider,1996), so it is important to make distinction between rote learning and meaningful learning which leads to comprehension. Dual Coding Theory is second theoretical base for them in which the interconnection of two verbal and visual systems of the memory facilitate the interpretation of the text and also make it easier to retain and retrieve (Clark \& Paivio, 1991). The last one is Cognitive Load Theory: this strategy claims that they have the abilities to decrease the cognitive aspects resulting in the condition that working memory is capable to get more learning material (Adcock, 2000).

\section{LITERATURE REVIEW}




\section{A. The Origions of Dynamic Assessment (DA)}

Lidz and Elliott (2000) claim that dynamic assessment focuses on approach which understands individual differences and their implications for instruction. Dynamic assessment procedures focus the process itself rather than the products of learning (Lidz \& Gindis, 2003).

DA has emerged from the work of Vygotsky in the Soviet Union and Feuerstein in Israel. Vygotsk's approach is a way to measure the zone of proximal development (ZPD) of a child and his or her ability to benefit from the help of a more experienced other. The more that a child can profit from meditation, the greater the ZPD is. The expressed goal of DA is modifying learners' performance during the assessment itself. Lantolf and Thorne (2006) discuss in the following way:

The present study is motivated by the need to shed some light on one of the main issues in TEFL, namely developing students' reading skill by taking some obstacles away, by which most of them encounter in the classrooms. One of these problems derived from the existence of unknown and unusual words that are in reading text. The second problem refers to the not existence of awareness about the organization of the text". Pertaining to these issues, the study was set up to investigate the effect of three reading comprehension strategies namely, Graphic Organizers (GO), L1 Marginal Glossing (MG) and traditional instruction on reading comprehension achievement of the EFL learners. Throughout the ten sessions of the study, the researcher gathered data to measure the effectiveness of these techniques in improving students' reading comprehension ability. The study was guided by two research questions and related hypotheses.

\section{Dynamic Assessment vs. Statistic Assessment}

Bachman (1990) believes that since, the assessment is an index of the individual true ability, testers should be careful about language proficiency. But in a NDA the abilities will be affected due to the assessment means and the testing context McNamara (2004).

As Vygotsky (1998) states it the results of conventional assessment models look like an empty medical diagnosis in which a doctor's "job is merely restating the patients" known problem in a scientific term (p. 205).

Vygotsky (1998) believes that this kind of diagnosis is unacceptable and must be changed with a kind of "True Diagnosis" something that includes "an explanation, prediction and scientific basis for practical description" (p.205). DA tries to do that therefore the conventional and traditional terms applied in NDA procedures such as generalizability do not apply in DA. (as cited in Malmeer \& Zoghi, 2014)

\section{Mediation in Dynamic Assessment}

Mediated assistance is a very specific form of feedback which is provided in DA, and this is the heart of the assessment process. The mediation can be presented in two formats: sandwich or cake. The sandwich format typically consists of three stages: pre-test $\rightarrow$ mediation (instruction) $\rightarrow$ post-test. That is, first, test-takers are asked to complete pre-test activities; second, they are given instruction (planned in advance or adjusted to test-takers' needs taking into account their performance during the initial test), and finally, they move on to a series of post-tests. This DA format is labeled as "sandwich" because instruction usually occurs between pre-test and post-test stages throughout the test administration. In sandwich format, instruction may be given in individual or group settings to promote test takers' development. Within the layer-cake format, assessment comprises intervention (or feedback) from the examiner during the test administration itself. In this DA format, the examinees carry out testing activities that are given item by item. If they cannot answer an item correctly, they are provided with instruction in the form of pre-fabricated hints (Hessamy \& Ghaderi, 2014).

The cake format lends itself to individual administration in that the examinee is provided with instruction during the assessment process itself. The examinee's ability to learn is measured during the process of learning and feedback is given until the examinees succeed in doing the task or giving it up (Hessamy \& Ghaderi, 2014).

\section{B. Graphic Organizers $(G O)$}

Different learning strategies seem to provide readers different ways to successfully understand the text (Anderson and Pearson,1984; Grabe, 1999; Grabe \& Stoler, 2001), among these different strategies, graphic organizer is the one that is supported by many researchers as an effective one, in promoting comprehension (Blachowicz \& Ogle, 2001; Conley,2008; Ellis \& Howard, 2005; Grabe \& Jiang, 2007; Graves, Juel \& Graves, 2006; Jiang, 2012; Ozturk, 2012; Vacca \& Vacca, 1999).

Graphic organizers are set of visual devices that portray information in different ways. They use such items as lines, circles, and boxes to form images, which show the usual ways in which information is typically organized: hierarchic, cause and effect, compare / contrast, and cyclic or linear sequences. They serve as visual cues to facilitate communication or understanding of information by showing how essential information about a topic is organized (Ellis \& Howard, 2005).

GOs can be effective if:

- The complexity and difficulty of the GO shape is developmentally suitable for intended students' background knowledge and experience with GO.

- Students' zone of proximal development matches the level of scaffold assistance associated with using the GO.

- The complexity and density of the information to be communicated on the GO is appropriate in relation to students' background knowledge of the information or closely related topics. 
Given students' scripting ability, the size of the space for which information is to be noted by students on the GO is sufficient.

- Students' reading and scripting skills are sufficiently developed so that they can independently read what they noted on the GO at a later time (Ellis \& Howard, 2005).

According to Ellis and Howard (2005) GOs work best when instruction is informed, explicit, intentional, and scaffold.

\section{Effects of Graphic Organizer in Learning}

To summarize the issue, GOs are a bundle of learning strategies which include translating words expressed in linear form into visual structures. When written and hard concepts are expressed graphically, the students can use other structures for understanding the course concepts. GOs also increase students' ability to learn to reject the arguments. While GOs are some established cognitive tools to promote learning, they also help students with differing learning styles in their attempt to master legal analysis. So, the role of learning styles in the law school classroom is emphasized. Meanwhile, GOs may help students learn analysis because they visualize relationships, steps or chronology through showing the spatial relationship between the ideas (McElroy \& Coughlin, 2009).

It should also be mentioned that GOs may have a positive effect on reading comprehension (I.A.R.E., 2003). It's believed that the reading comprehension skills of students in elementary and secondary schools improve with the introduction of GOs. The National Reading Panel (2000) in the United States studied the research literature on reading comprehension and expressed that GOs are one of the seven most effective teaching strategies for reading comprehension. It was also proven that the teachers who include GOs in their instructional practice can improve their students' academic performance (as cited in I.A.R.E., 2003). Other results from three different studies showed that"GOs are a helpful method for improving student retention and recall of information for both elementary and junior high students with learning disabilities, as well as upper elementary students" (as cited in Zaini, Mokhtar, \& Nawawi, 2010, p. 18 ).

\section{Graphic Organizer in Reading Comprehension}

A simple investigation of the recent literature of reading showed that students should have a number of reading strategies at their disposal. Many researchers claimed that reading strategies are helping tools which contribute to reading abilities. Also, in overall reading comprehension abilities, awareness of text organization is a key factor (Pearson \& Fielding, 1991; Trabasso \& Bouchard, 2002).

One of the most important ways to recognize discourse structuring in texts is through the use of graphic organizer (GOs) - visual representation of information in the text. Prior to 1969, advance organizers had been introduced as prose passages. Baron (1969) modified them into tree diagrams for vocabulary acquisition. He termed this diagram as "the structured overview". A structured overview is a "diagrammic representation of the basic vocabulary of a unit so as to show relationships among the concepts represented by those words" (Earle, 1969, p.4).

Graphic organizer is defined as spatial arrangements and wording that organizes key conceptual relationships graphically (Bean and etal, 1986). These GOs represent information as a semantic web or as an outline of main ideas in a text. These semantic webs highlight discourse structure of the texts. In other words, sketching a semantic map or graphic organizer is exactly the same as getting an $\mathrm{x}$ - ray in that it shows the deeper skeletal parts vividly. Fishbone diagram, cause and effect, pie chart, semantic feature analysis, cloud, continuum scale, comparison and contrast matrix are clarified as some different types of graphic organizers (as cited in Rostami Sarabi, 2012).

\section{METHODOLOGY}

\section{A. Purpose and Research Questions of the Study}

The present makes an effort to shed some light on one of the main issues in TEFL, namely developing students' reading skill by taking some obstacles away, by which most of them encounter in classrooms. One of these problems derived from the "existence of unknown and unusual words in reading text". The second one refers to the "lack of awareness about the organization of the text".(Larijani, and etal, 2015) Pertaining to these issues, the study was set up to investigate the effect of thee reading comprehension strategies namely, Dynamic Assessment (DA), Graphic Organizers (GO), and traditional instruction on reading comprehension achievement of the EFL learners. Throughout the ten sessions of the study, the researcher gathered data to measure the effectiveness of these techniques in improving students' reading comprehension ability. The study had two research questions and related hypotheses:

RQ1: Does the type of reading strategy used (dynamic assessment vs. graphic organizers) differentially influence students' reading comprehension?

RQ2: Which strategy has the most effect on students' reading comprehension?

Moreover, the following hypotheses were developed accordingly:

$\mathrm{RH}_{1}$ : The type of reading strategy used (dynamic assessment vs. graphic organizers) can differentially influence students' reading comprehension.

RH2: It is thought that dynamic assessment will have the most influence on students' reading comprehension.

\section{B. Participants}

To accomplish the task, 90 students participated in this study. The participants included female and male students studying at Payame Noor University of Ardabil. In order to establish the homogeneity of the subjects in terms of 
language proficiency, Oxford Placement Test (OPT) was given to the subjects and based on their performance on this test 45 students in elementary level were selected to take part in the main phase of the research. These students were divided into three equal groups: Dynamic Assessment (DA), Graphic Organizers (GO) and Traditional Instruction (TI). Each group comprised of 15 students.

\section{Instrumentation}

The materials used in this study included a packet consisting of a standardized proficiency test, i.e. Oxford Placement Test (OPT) devised by Edwards (2009), reading passages for treatment sessions and a reading comprehension test which served both as pretest and posttest.

\section{Procedure}

The study composed of 10 sessions. It was an experimental study incorporating one dependent and one independent variable. The dependent variable was the reading comprehension ability of students and the independent variable was strategy type, which had 3 levels, namely, DA, GO and TI.

\section{DISCUSSION}

In order to determine proficiency level of 90 participants, Oxford Placement Test (OPT) was administered (Table 1). Consequently, the number of homogenous elementary level students who were selected to take part in the next stage were 45.

TABLE 1.

DESCRIPTIVE STATISTIC FOR SCORES ON THE PROFICIENCY TEST

\begin{tabular}{lllll}
\hline $\mathrm{N}$ & Mean & SD & Min & Max \\
\hline 90 & 19 & 5.94 & 7 & 42 \\
\hline
\end{tabular}

Once the outliers were excluded, the supposedly homogeneous participants $(n=45)$ were assigned to three equal groups.

In the second session, the researcher administered the pretest to examine the three groups in terms of reading comprehension. Since most of the texts in the students' books were not in sequential frame, some sequential texts were prepared by the researcher from other sources (course books and some texts were retrieved from the internet). The researcher chose ten texts from the books and internet as unseen and 10 texts from their course books, namely seen texts. To compare their readability and make sure that the sequential texts suited their level, readability was calculated, using Flesh Reading Ease in Microsoft Word. 2007, and then a $\mathrm{t}$ - test was run among two groups texts.

Table 2 shows descriptive statistics for these passages and Table 3 depicts the result of t-test, which reveals no statistically significant difference in the mean scores of two groups of texts $(t(18)=0.601, p=0.56)$. Therefore, the researcher decided to choose these texts to be used in pretests and posttests and during treatment sessions.

TABLE 2.

DESCRIPTIVE STATISTICS FOR THE TEXT READABILITY STATISTIC

\begin{tabular}{llll}
\hline Group & N of texts & Mean & SD \\
\hline Seen & 10 & 87 & 3.6 \\
\hline Unseen & 10 & 86.25 & 7.9 \\
\hline
\end{tabular}

TABLE 3.

INDEPENDENT SAMPLES T-TEST TO COMPARE READABILITY OF THE TEXTS

\begin{tabular}{llllll}
\hline \multicolumn{2}{l}{ Levene's Test for Equality of Variances } & & \multicolumn{3}{l}{ t-test for Equality of Means } \\
\hline & $\mathrm{F}$ & $\mathrm{Sig}$ & $\mathrm{T}$ & $\mathrm{Df}$ & Sig. (2-tailed) \\
\hline Equal variances assumed & 5.82 & 0.027 & 0.601 & 18 & 0.556 \\
Equal variances not assumed & & & 0.601 & 12.561 & 0.559 \\
\hline
\end{tabular}

After administering OPT, the researcher administered the pretest in order to examine the groups in terms of their reading comprehension of texts with sequential frame. Table 4 demonstrates the descriptive statistics for pretest scores.

TABLE 4.

DESCRIPTIVE STATISTICS FOR SCORES ON PRETEST

\begin{tabular}{llllll}
\hline Groups & $\mathrm{N}$ & Mean & SD & Min & Max \\
\hline Group A & 15 & 10.3 & 2.46 & 7 & 15 \\
Group B & 15 & 10.7 & 1.92 & 8 & 14 \\
Group C & 15 & 10.3 & 1.92 & 9 & 12 \\
\hline
\end{tabular}

As understood from Table 4, the mean scores of three participating groups are almost close to each other and, accordingly, groups can be regarded as homogenous in terms of reading proficiency. Figure 1 graphically shows the result. 


\section{Pretest Scores}

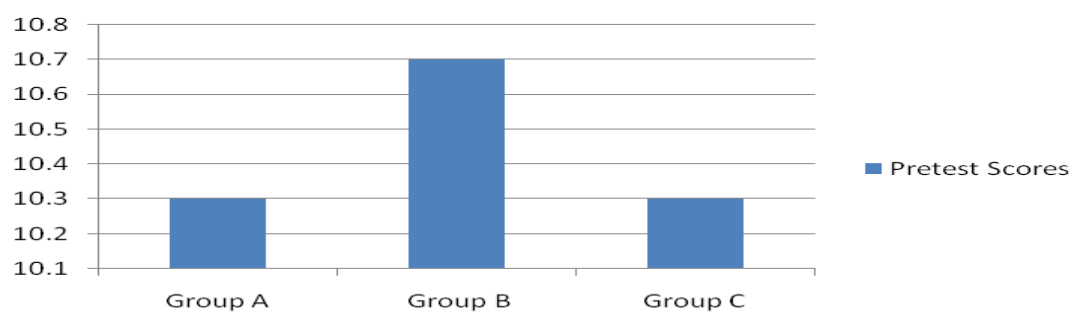

Figure 1 Performance of three participating groups on pretest

An ANOVA was necessary to see if there was any significant difference between the groups in terms of their reading ability. First, a normality test was run to make sure the scores were normally distributed. As shown in Table 5, the difference did not reach significance level (sig. $=0.20)$, hence the scores were of normal distribution.

TABLE 5.

NORMALITY CHECK FOR THE SCORES ON PRETEST TEST

\begin{tabular}{lll}
\hline Kolmogorov - Smirnov & & \\
\hline Statistic & Df & Sig. \\
\hline 108 & 39 & 0.200 \\
\hline
\end{tabular}

Since the data were normally distributed, an ANOVA was run. Table 6 depicts the result. As it can be seen, there was no significant difference among the mean scores on pretest for the three groups. $(p=0.80)$.

TABLE 6.

ONE-WAY ANOVA ON PRETEST SCORES

\begin{tabular}{llllll}
\hline & Sum of squares & df & Mean squares & F & Sig. \\
\hline Between groups & 1.59 & 2 & .795 & .213 & .809 \\
Within groups & 134.15 & 36 & 3.72 & & \\
Total & 135.74 & 38 & & & \\
\hline
\end{tabular}

In the following session, in group $\mathrm{A}$, in dynamic assessment phase, the mediator provided individualized mediation and assistance, including prompts, hints, suggestions, explanation, etc. in a justifiable and meaningful way, where necessary.

The mediator was cautious about the problematic areas from pretest phase and additional problems that the learner revealed through interactions in this phase. Through DA, the mediator tried to help the learner optimally with the help of mediation. The mediator interrupted at various points to ask questions, offer suggestions, and provide help when necessary; sometimes he interrupted to provide a correction, to question something that was said, or to make general comments.

The mediator also encouraged students to ask him for help in case of need. When a student used incorrect forms in answering questions, the researcher provided a series of graduated prompts, arranged from implicit to explicit, to help the student reformulate the form correctly.

In group B (GO), the participants were given instruction on how to use GOs. As Chiang (2005) states there were three stages in constructing a new learning strategy, with Modeling as the first stage; at this stage, the teacher first showed the students how a strategy is employed and why it is worth learning. After reading the passage, the instructor drew a graphic organizer special for sequential text on the board showing how to write stage by stage the relevant information in order to have organized and visual knowledge about the passage. In the second stage - guided practicestudents were asked to share suggestions for what to add to each section and explain why. Then the instructor asked them to organize the text in groups under the guidance and supervision of the teacher. In the end, they were asked to apply GO strategy individually (independent application). This cycle continued in the 6 coming sessions. At the end of each session, the students were going to answer related multiple choice tests.

The instruction in group $\mathrm{C}$ was conducted by another teacher and basically followed traditional principles. The teacher in this group read the text loudly and students repeated each sentence after the instructor. The passage was then translated into (first language) and the students started to answer the following reading comprehension questions.

In the last session four reading comprehension passages with 20 related questions (12 multiple-choice and 8 true/false) were presented as posttest. Descriptive statistics for groups' performances on the posttest are presented in table 7 .

TABLE 7.

DESCRIPTIVE STATISTICS FOR SCORES ON POSTTEST

\begin{tabular}{llllll}
\hline Groups & $\mathrm{N}$ & Mean & SD & Min & Max \\
\hline Group A & 15 & 16.23 & 2.00 & 13 & 19 \\
\hline Group B & 15 & 14.15 & 2.26 & 11 & 18 \\
\hline Group C & 15 & 12.92 & 1.32 & 11 & 15 \\
\hline
\end{tabular}


Repeatedly, in order to select the appropriate statistical analysis, test of Normality was run. The results, as shown in Table 8, indicated that the Normality was violated (sig. $=0.001$ ).

TABLE 8.

NORMALITY CHECK FOR THE SCORES ON POSTTEST

\begin{tabular}{lcc}
\hline Kolmogorov - Smirnov & & \\
\hline Statistic & Df & Sig. \\
\hline 168 & 39 & .00 \\
\hline
\end{tabular}

Since the distribution was not normal, the Kruskal-Wallis Tests, which is the non-parametric alternative to one-way between groups analysis of variance, was chosen to compare the scores for three groups. The results of this test, presented in Table 9, revealed a statistically significant difference between three groups in terms of their performance on posttest (sig. $=0.00)$.

TABLE 9.

THE KRUSKAL - WALLIS TESTS FOR THE SCORES ON POSTTEST

\begin{tabular}{ll}
\hline Chi-Square & 13.08 \\
Df & 2 \\
Asymp.Sig & 0.001 \\
\hline
\end{tabular}

Although a statistically significant result for Kruskal Wallis Test was obtained, it was not clear which groups were statistically and significantly differing from the other one. To find out this, the researcher did some follow-up Mann Whitney $U$ tests between the pairs of groups. In this phase, the use of Bonferroni correction to the alpha value was necessary in order to control for Type 1 errors. To do this correction, the alpha level of .05 was divided by the number of comparisons that was intended to be used. The revised alpha level as criterion for determining significance was $0.05 / 3=.016$. Table 10 shows the results of the comparisons.

TABLE 10.

MANN-WHITNEY U AS A POST - HOC COMPARISON AMONG GROUPS

\begin{tabular}{ll|lll}
\multicolumn{5}{c}{ MANN-WHITNEY U AS A POST - HOC COMPARISON AMONG GROUPS } \\
\hline Groups & \multicolumn{2}{l}{ Z } & Asymp.Sig & Effect Size \\
\hline DA & GO & -2.280 & .02 & 0.0876 \\
\hline DA & TI & -3.050 & .00 & 0.1173 \\
\hline GO & TI & -1.408 & .16 & 0.0541 \\
\hline
\end{tabular}

The result of this comparison showed that the difference between DA and GO $(Z=-2.28, p=0.02)$ was not significant. The difference between DA and TI, however, reached significance $(Z=-3.050, P=0.00)$ although, the effect size was small (0.11). The difference between $\mathrm{GO}$ and TI was not significant $(\mathrm{Z}=-1.408, \mathrm{P}=0.16)$.

\section{CONCLUSION}

The main purpose of this study was to measure the effect of using three reading comprehension strategies of GO, DA and TI on EFL students' reading comprehension ability. As results showed, students who used DA outperformed those who received GO and TI.

On the other hand, through the use of dynamic assessment procedures with standardized test instruments, more insight into the reading profile of the student can be achieved. Thus, this can be advantageous to the assessor, because the results of dynamic assessment in reading can provide information for instructional programming. Most importantly, it is the student who can profit most from dynamic assessment than Graphic Organizers. Because their reading abilities can be more accurately assessed which can, in turn, lead to higher level of reading performance. Similarly, the researcher can affirm that the paradigm of dynamic assessment is useful in the domain of EFL learning but not in the field of general cognitive performance.

The noteworthy thing to say is that, as Schundler (1992). claims, education should be concerned not just with theories of instruction, but with learning to learn, developing skills and strategies to continue to learn, with making learning experiences meaningful and relevant to the individual, with developing and growing as a whole person.

Finally and to summarize the issue, DA intervention in the form of mediation was shown to have a significant role in the diagnostic perspective of students' problem areas. The procedure section provides a lot of examples showing that in many cases that the students were not able to display their second language during the independent performance but they could overcome the problem after receiving implicit or explicit assistance provided by researchers or rather the mediators. (Nazari, \& Mansouri, 2014)

\section{REFERENCES}

[1] Adcock, A. (2000). Effects of cognitive load on processing and performance. Retrieved January23, 2005, from University of Memphis Instructional Media Lab Website: http://aimlab. memphis.edu/amyscogpaper.pdf.

[2] Anderson, R. C., \& Pearson, P. D. (1984). A schema-theoretic view of basic processes in reading comprehension. In P. D. Pearson (Ed.), Handbook of reading research (pp. 255-291). New York: Longman. 
[3] Armbruster, B., Anderson, T., \& Ostertag, J. (1987). Does text structure/summarization instruction facilitate learning from epository texts? Reading in Foreign Language 22(4): 331-346.

[4] Bachman, L F. (1990). Fundamental considerations in language testing. Oxford: Oxford University Press

[5] Barron, M. E. (1969). A note on the historical development of logic diagrams: Leibniz, Euler, and Venn, Mathematical Gazette, 53:113-125.

[6] Bean, T. W., Singer, H., Sorter, J., \& Frazee, C. (1986). The effect of metacognitive instruction in outlining and graphic organizer construction on students' comprehension in a tenth-grade world history class. Journal of Reading Behavior, 18(2): 153-169.

[7] Blachowicz, C. \& Ogle, D. (2001). Reading comprehension: Strategies for independent learners. New York: The Guilford Press.

[8] Cain, K., Oakhill, \& Bryant, P. E. (2004). Children's reading comprehension ability: Concurrent prediction by working memory, verbal ability, and component skill. The Modern Language Journal, 96, 31-42.

[9] Chiang, C. (2005). The effect of graphic organizers on Taiwanese Tertiary Students' EFL reading comprehension and attitudes towards reading in English. (Unpublished Doctoral Dissertation). Australian Catholic University

[10] Clark, J M., \& Paivio, A. (1991). Dual coding theory and education. Journal of educational psychology review, 3 (3), 149-170.

[11] Conley, G. K. (2008). The effect of graphic organizers on the academic achievement of high school students in the United States history who receive instruction in a blended, computer- based learning environment (unpublished Doctoral Dissertation). Education Liberty university.

[12] Dye, G. A. (2000). Graphic organizers to the rescue! Helping students link students link and remember information. Teaching Exceptional Children, 32 (3), 72-76.

[13] Earle, R.A. (1969). Use of structured overview in mathematics classes. In H.L. Herber \& P.L Sanders (Eds.), Research in reading in the content areas: First year report. Syracuse, NY: Syracuse University Press.

[14] Ellis, E. S. \& Howard, P. W. (2005). Graphic organizers. Power tools for teaching students with learning disabilities. Retrieved September 12, 2013 from www. Teaching LD. Org.

[15] Engelmann, S., \& Carnine, D. W. (1982). Theory of instruction: Principles and applications. New York: Irvington.

[16] Gernsbacher, M. A. (1990). Language comprehension as structure building. Hillsdale, NJ: Erlbaum.

[17] Glutting, J.J. and P.A. McDermott. (1990). Principles and problems in learning potential. In. C .R. Reynolds and R.W. Kamphaus, Handbook of Psychological and Educational Assessment of Children Intelligence and Achievement. New York: Guilford.

[18] Grabe, W. (1999) Developments in reading research and their implications for computer-adaptive reading assessment. In M. Chalhoub-Deville (Ed.), Issues in computer-adaptive testing of reading proficiency (pp. 11-48). Cambridge, Uk: Cambridge University Press.

[19] Grabe, W. \& Jiang, X. (2007). Graphic organizers in reading instruction: Research findings and issues. Reading in a Foreign Language. 19(1), 34-55.

[20] Grabe, W. \& Stoler, F. L. (2001). Teaching and researching reading. London: Longman.

[21] Graves, M.F., Juel, C., \& Graves, B.B. (2006). Teaching reading in the 21st century (4th Edition), Needham Heights, MA: Allyn \& Bacon, Inc.

[22] Griffin, C. C., \& Tulbert, B. L. (1995). The effect of graphic organizers on students' comprehension and recall of expository text: A review of the research and implications for practice. Reading and Writing Quarterly, 11, 73-89. doi:10.1080/1057356950110106.

[23] Hessamya, G., \& Ghaderib, E. (2014). The role of dynamic assessment in the vocabulary learning of Iranian EFL learners, Procedia - Social and Behavioral Sciences, 98, 645 - 652.

[24] Institute for the Advancement of Research in Education (I.A.R.E.). (2003). Graphic organizers: A review of scientifically based research. Charleston, WV: Institute for the Advancement of Research in Education

[25] Jiang, X. (2012). Effects of discourse structure graphic organizers, Reading in a Foreign Language 24 (1), 84-105.

[26] Johnson-Laird, P. N. (1983). Mental models. Cambridge, England: Cambridge University Press.

[27] Kintsch, W. (1998). Comprehension: A paradigm for cognition. New York: Cambridge University Press

[28] Klinger, J. K., \& Geisler, D. (2008). Helping classroom reading teachers distinguish between language acquisition and learning disabilities. In J. K. Klinger, J. J. Hoover, \& L. M. Baca (Eds.), why do English language learners struggle with reading? Distinguishing language acquisition from learning disabilities (pp. 57-74). Thousand Oaks, CA: Corwin.

[29] Lantolf, J. P. \& Thorne, S. L. (2006). Sociocultural theory and the genesis of second language development. Oxford: Oxford University Press.

[30] Larijani, L., Bagherzadeh Kasmani, M., Banou Sabouri, N. (2015). Exploring the Effects of First Language Reading on Second Language Reading across Different Proficiency Levels, Theory and Practice in Language Studies, V: 5, N: 3.

[31] Lidz, C.S. \& Elliott, J.G. (Eds). (2000). Dynamic assessment: prevailing models and applications. Amsterdam: JAI/Elsevier Science

[32] Lidz, c. s. \& Gindis, B. (2003). Dynamic assessment of the evolving cognitive functions in children. In Vygotsky's educational theory in cultural context. A. Kozulin, B. Gindis, V. S. Ageyev, \& S. M. Miller (Eds). Cambridge: Cambridge University Press.

[33] Malmeer, E., \& Zoghi, M. (2014). Dynamic Assessment of Grammar with Different Age Groups. Theory and Practice in Language Studies, 4(8), 1707-1713.

[34] Marzano, R. J., Pickering, D. J., \& Pollock, J. E. (2001). Classroom instruction that works. Research-based strategies for increasing student achievement. Upper Saddle River, N.J.: The USA. Merrill education/ASCD college textbook series. Pearson/Merrill Prentice Hall.

[35] McElroy, L. T., \& Coughlin, C. N. (2009). The other side of the story: Using graphic organizer as cognitive learning tools to teach students to construct effective counter-analysis. Unpublished thesis University of Baltimore Law Review.

[36] McNamara, T. (2004). Language testing. In Davies and C. Elder (Eds.), The Handbook of Applied Linguistics (pp. 763-783). AMalden, MA: Blackwell. 
[37] Meyer, B.J., \&, Ray, R.O. (2011). Individual differences in children's knowledge of expository text structures: A review of literature. International Electronic Journal of Elementary Education, 4(1), 67-82.

[38] Nazari, B. \& Mansouri, S. (2014) Dynamic assessment versus static assessment: A study of reading comprehension ability in Iranian EFL learners. Journal of Language \& Linguistics Studies. Vol. 10 Issue 2, p134-156. 23p.

[39] Ozturk, O., (2012). The effects of Graphic organizers on reading comprehension achievement of EFL Learners. Pamukkale University, 32, 37-45.

[40] Pearson, P. D., \& Fielding, L. (1991). Comprehension instruction. In R. Barr, M. Kamil, P. Mosenthal \& P. D. Pearson (Eds.), Handbook of Reading Research (Vol. II, pp. 815-860). New York: Longman.

[41] Saavedra, L. (1999). Dual coding theory: A theoretical foundation of learning with graphics Retrieved January 15, 2005, from George Mason University Web site: //chd.gse.gmu.edu/immersion/knowledgebase/strategies/cognitivism/DualCodingTheory.hm.

[42] Rostami Sarabi, Z. (2012). The Effect of Graphic Organizer and Marginal L2 Glossing Training on the Reading Comprehension of ESP Students. Researcher, 4(4), 16-23. http://www.sciencepub.net/researcher.

[43] Schundler, E. T. (1992). The Effect of cooperative Learning on Comprehension: An analysis of the effect of modified CIRC instructional approach and cooperative learning partnerships on reading comprehension. (Unpublished Doctoral Dissertation). Kean College of New Jersey.

[44] Trabasso, T., \& Bouchard, E. (2002). Teaching readers how to comprehend text strategically. In C. C. Block \& M. Pressley (Eds.), Comprehension instruction: Research-based best practices (pp. 176-200). New York: Guilford Press.

[45] Vacca, R. \& Vacca, J. (1999). Content area reading: Literacy and learning across the curriculum. New York: Longman.

[46] Vygotsky, L. S. (1998). The Problem of Age. In The Collected Works of L. S. Vygotsky. Vol. 5. Child Psychology. New York: Plenum.

[47] Winn, W., \& Snider, D. (1996). Cognitive perspectives in psychology. In D. H. Jonassen (Ed), Handbook of research for educational communications and technology. New York: Simon and Schuster MacMillan.

[48] Zaini, S. H., Mokhtar, S. Z., \& Nawawi, M. (2010). The Effect of Graphic Organizer on Students' Learning in School Types of Graphic Organizer. Malaysian Journal of Educational Technology, 10, 17-23.

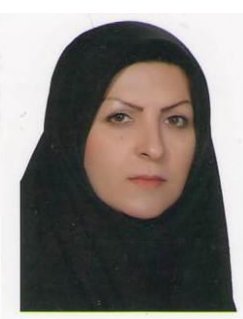

Malahat Shabani Minaabad is an assistant professor of Applied Linguistics at Payame Noor University, Ardabil, Iran. She got her PhD in Applied Linguistics from Baku State University of Azerbaijan in 2010, and MA in TEFL from Khatam University of Tehran, Iran in 2001. Since then, she has been involved in teaching $\mathrm{MA}$ and $\mathrm{PhD}$ students and enjoys supervising MA and $\mathrm{PhD}$ dissertations.

Since Malahat Shabani has been more interested in the field of linguistics and teaching, she has published so many articles in the mentioned fields. 